\title{
Altered N100-potential associates with working memory impairment in Parkinson's disease
}

\section{Annanmaki, Tua}

$2017-10$

Annanmaki , T , Palmu , K, Murros , K \& Partanen , J 2017 , ' Altered N100-potential associates with working memory impairment in Parkinson's disease ' , Journal of Neural

Transmission , vol. 124 , no. 10 , pp. 1197-1203 . https://doi.org/10.1007/s00702-017-1758-z

http://hdl.handle.net/10138/298057

https://doi.org/10.1007/s00702-017-1758-z

publishedVersion

Downloaded from Helda, University of Helsinki institutional repository.

This is an electronic reprint of the original article.

This reprint may differ from the original in pagination and typographic detail.

Please cite the original version. 


\title{
Altered N100-potential associates with working memory impairment in Parkinson's disease
}

\author{
Tua Annanmaki ${ }^{1}$ (1) $\cdot$ Kirsi Palmu $^{2} \cdot$ Kari Murros $^{1} \cdot$ Juhani Partanen $^{3}$
}

Received: 21 April 2017/Accepted: 7 July 2017/Published online: 14 July 2017

(C) Springer-Verlag GmbH Austria 2017

\begin{abstract}
The diagnosis of cognitive impairment and dementia often occurring with Parkinson's disease (PD) is still based on the clinical picture and neuropsychological examination. Ancillary methods to detect cognitive decline in these patients are, therefore, needed. Alterations in the latencies and amplitudes of evoked response potential (ERP) components N100 and P200 have been described in PD. Due to limited number of studies their relation to cognitive deficits in PD remains obscure. The present study was designed to examine if alterations in the N100- and P200-potentials associate with neuropsychological impairment in PD. EEG-ERP was conducted to 18 PD patients and 24 healthy controls. The patients underwent a thorough neuropsychological evaluation. The controls were screened for cognitive impairment with Consortium to Establish Alzheimer's disease (CERAD) - testing and a normal result were required to be included in the study. The N100latency was prolonged in the patients compared to the controls $(p=0.05)$. In the patients, the N100 latency correlated significantly with a visual working memory task $(p=0.01)$. Also N100 latency was prolonged and N100 amplitude habituation diminished in the patients achieving poorly in this task. We conclude that prolonged N100-
\end{abstract}

Tua Annanmaki

tua.annanmaki@gmail.com

1 Clinical Neurosciences, Neurology, University of Helsinki and Jorvi Hospital of Helsinki University Hospital, Espoo, Finland

2 Clinical Neurosciences, Clinical Neurophysiology, University of Helsinki and Helsinki University Hospital, Espoo, Finland

3 Clinical Neurosciences, Clinical Neurophysiology, University of Helsinki and Jorvi Hospital of Helsinki University Hospital, Espoo, Finland latency and diminished amplitude habituation associate with visual working memory impairment in PD.

Keywords Evoked response potential · Cognition · Parkinson's disease

\section{Introduction}

Parkinson's disease (PD) is a complex neurodegenerative disorder with motor, autonomous and cognitive symptoms. The motor symptoms dominate the clinical picture especially in the early stages of the disease. However, neuropsychological testing often reveals subtle cognitive changes typical of PD even at the early stages of the disease. Verbal and visual memory deficits, executive dysfunction, problems in language and attention are the most prevalent findings (Aarsland et al. 2008; Muslimovic et al. 2005; Pfeiffer et al. 2014; Uc et al. 2005) that in some patients deepen to the level of mild cognitive impairment (PD-MCI). As the disease progresses, the neuropsychological symptoms tend to advance and a substantial proportion of the patients with PD-MCI will develop Parkinson's disease dementia (PDD) during its course (Aarsland et al. 2003; Pigott et al. 2015; Riedel et al. 2008). Movement Disorder Society has recently published guidelines to diagnose both PD-MCI (Litvan et al. 2012) and PDD (Emre et al. 2007). According to the guidelines the diagnosis of PD-MCI and PDD are based on clinical and neuropsychological evaluation and ruling out other causes. As to date, there are no clinically applicable ancillary methods to establish PD-MCI or PDD. The situation is, therefore, different from the other common dementias, such as Alzheimer's disease and vascular dementia, where brain imaging findings are an essential 
part of the diagnosis. New methods to examine cognition in PD are needed not only to diagnose dementia but also to identify at-risk patients to support the preservation of cognition and hopefully in the future offer medication to prevent future cognitive decline.

Electroencephalogram (EEG) with evoked response potentials (ERP) is a safe and non-invasive method in providing real-time information of the brain's response to sensory stimuli indicating not only stimulus detection but also ensuing conscious processing and orienting to novel stimuli. The ERPs have been examined in Parkinson's disease (Green et al. 1996; Hayashi et al. 1996; Hozumi et al. 2000; Katsarou et al. 2004), mild cognitive impairment (Bennys et al. 2011), Alzheimer's disease (Lai et al. 2010) and schizophrenia (Hasey and Kiang 2013) but there are no clinical applications in this field. In PD, the main focus of research has been on the late component P300, latency of which is usually prolonged in PD-MCI and PDD or the response may be absent altogether. P300 latency and amplitude have also been found to correlate to neuropsychological disturbances such as impaired executive function and verbal fluency indicating that alterations in P300 reflect frontal lobe dysfunction in PD (Chen et al. 2006; Tsuchiya et al. 2000).

Previous studies examining N100- and P200-potentials in PD are few and the results have been contradictory. The P200 response is considered to reflect conscious stimulus processing, which is often impaired or at least slowed in PD. Accordingly, the latency of $\mathrm{P} 200$ has been prolonged in some studies (Ebmeier et al. 1992; Hansch et al. 1982) but also normal results have been reported (Goodin and Aminoff 1987). Also the N100 latency has been reported normal in a number of studies concerning PD (Pekkonen et al. 1995; Vieregge et al. 1994). This is rather unexpected considering that the N100-potential most likely indicates stimulus detection and is, therefore, a measure of attention. It also associates with working memory by directing attention towards meaningful sensory information and blocking redundant stimuli (Lee et al. 2010). Sustaining attention and ignoring irrelevancies are often impaired in PD as well as is working memory. Considering these common cognitive deficits in PD as well as the cognitive processes that the P200- and N100 potentials are considered to measure, one would expect to find some association between P200- and N100 potentials and neuropsychological test performance.

In the present study, we conducted EEG with ERPs to 18 PD-patients and 24 healthy controls to investigate neurophysiological differences between the groups. We hypothesized that there would be alterations in the evoked response potentials in the patient group and that these alterations would reflect cognitive changes. Therefore, also a neuropsychological examination was done for patients.

\section{Methods}

14 PD-patients were recruited from a previously described population (Annanmaki et al. 2008). Due to dropouts in the primary sample, 4 additional consecutive PD-patients from the Neurological Outpatient Clinic of Jorvi Hospital of Helsinki University Central Hospital (HUCS) were invited to participate to the study. Inclusion criteria were idiopathic PD according to the UK Parkinson's disease Brain Bank Criteria(Hughes et al. 1992) and no clinical sign of Parkinson's disease dementia. Exclusion criteria were current use of medications affecting plasma uric levels other than levo-dopa. All the patients were examined by a neurologist to evaluate Unified Parkinson's disease Rating Scale (UPDRS) motor score, Hoehn\&Yahr stage and Mini Mental State Examination (MMSE).

The controls were healthy volunteers from the hospital staff and their acquaintances with no sign of a neurological disease. Cognition was screened with Consortium to establish Alzheimer's disease (Cerad) -test series; a normal result was required to exclude mild cognitive impairment.

The demographic variables of the patients and controls are described in Table 1.

The study was approved by the Ethics Committee of Helsinki and Uusimaa Health District Area. All patients and controls signed a written informed consent.

\section{Recording and quantification of electroencephalography}

EEG recording and stimuli to induce ERP were done with a Cognitrace EEG/ERP-system version 3.3 (ANT Neuro, Enschede, The Netherlands, later abbreviated ANT). EEG was recorded with active shielded 64-channel Waveguard EEG caps with electrode layout following the international 10-10-system, electrode material $\mathrm{Ag}-\mathrm{AgCl}$ (ANT) and with a DC-amplifier REFA-64 (ANT) using sampling frequency of $256 \mathrm{~Hz}$. Cognitrace's amplifier uses inbuilt common average reference and it is constructed for direct current (DC) measurements and hence no high-pass filtering was applied. Impedances were made as low as possible. Timing of the different stimuli and responses were recorded together with the EEG.

Electro-oculogram (EOG) and electrocardiogram (ECG) were also recorded.

\section{ERP-recording}

During ERP-recording the patients were asked to follow a silent nature movie shown on a TV screen at a distance of 1.5 meters. Auditory stimuli were given through calibrated 
Table 1 The demographic characteristics of the patients and controls as well as the latencies and amplitudes on the N100 and P200 potentials

\begin{tabular}{lll}
\hline & PD-patients $(n=18)$ & Controls $(n=24)$ \\
\hline Age (range) & $62(42-71)$ & $67(60-79)$ \\
Gender, \% of males & $44 \%$ & $33 \%$ \\
MMSE (range) & $28(23-30)$ & $28(28-30)$ \\
Duration of disease in years, mean (range) & $6(2-13)$ & \\
UPDRS, mean (range) & $17(1-51)$ & \\
Levo-Dopa usage & 13 & \\
Levo-Dopa dose, mean (range) & $425 \mathrm{mg}(250-875 \mathrm{mg})$ & \\
Dopamine agonist & 12 & $95.1(16.6)^{*}$ \\
Selegiline & 13 & $-5.3(2.0)$ \\
N100 latency, mean (SD) & $107.6(23.2)^{*}$ & $214.6(21.5)$ \\
N100 amplitude, mean (SD) & $-5.5(2.0)$ & $4.3(1.7)$ \\
P200 latency, mean (SD) & $208.5(30.7)$ & \\
P200 amplitude, mean (SD) & $5.3(2.8)$ & \\
\hline
\end{tabular}

* Mann-Whitney $p=0.05$ headphones (Telephonics TDH-39P) and the patients were instructed not to pay attention to the tones.

The auditory ERPs were stimulated with pairs of tones with an inter stimulus interval (ISI) of $0.5 \mathrm{~s}$. The responses to first and second tones of pairs with $0.5 \mathrm{~s}$ ISI were analyzed. ERP responses for 40 pairs of stimuli were averaged. The interval between pairs of stimuli were $12 \mathrm{~s}$. The duration of the sound stimuli was $60.8 \mathrm{~ms}$ with rise and fall times of $11 \mathrm{~ms}$ each, leaving about $40 \mathrm{~ms}$ of steady plateau. Frequency of the stimuli was $1000 \mathrm{~Hz}$ and sound pressure level $60 \mathrm{~dB}$ above the hearing threshold, measured before the ERP recording and with the same tones as in the paradigm.

\section{EEG-ERP analysis}

The recordings were analyzed off-line using ASA software version 4.8.0 (ANT). Only channels of the international 10-20 system (Fp1, Fp2, F7, F3, Fz, F4, F8, T3, C3, Cz, $\mathrm{C} 4, \mathrm{~T} 4, \mathrm{~T} 5, \mathrm{P} 3, \mathrm{Pz}, \mathrm{P} 4, \mathrm{~T} 6, \mathrm{O} 1$ and $\mathrm{O} 2$ ) were considered in the analysis. All data was first inspected visually and the channels with excessive artifacts were removed prior to further analysis.

Pre-processing and analysis of the recordings were done with ASA-software version 4.6.2.0 (ANT). EEG was filtered with a bandpass of $0.3-30 \mathrm{~Hz}$ ( $12 \mathrm{~dB}$ /octave roll-off). Blink artefacts were removed by an algorithm based on spatial filtering (Ille et al. 2002). The manually selected prototypes of blinks per recording numbered at least ten. After artefact correction, the data were re-referenced to average reference and digitally filtered (high-pass $0.5 \mathrm{~Hz}$, low-pass $30 \mathrm{~Hz}, 24 \mathrm{~dB} /$ octave). Remaining artefacts were excluded with amplitude criterion of $\pm 75 \mu \mathrm{V}$ before calculating the averaged waveforms.
The continuous EEG data was transformed off-line to $600 \mathrm{~ms}$ epochs, starting $100 \mathrm{~ms}$ before the onset of each stimulus. Finally, the averaged waveforms were baseline corrected by the $100 \mathrm{~ms}$ preceding the stimulus as the baseline. The amplitude and latency of N100 (Cz) and P200 (Cz) elicited by the auditory stimuli were measured with respect to the highest negativity in a $60-170 \mathrm{~ms}$ post stimulus time interval and the highest positivity in a 100-260 ms interval, respectively. The results of the automated peak detection were verified manually and corrections performed when necessary. Habituation of the N100 was calculated as the difference between the amplitudes elicited by the first and second tones of a pair with $0.5 \mathrm{~ms}$ ISI.

\section{Neuropsychological examination}

Finnish translations of both traditional neuropsychological tests and computerized tasks were applied.

Depression was assessed with a 21-item version of the Beck Depression Inventory (BDI-II). General knowledge was assessed with the information and similarities subtests of the Wechsler Adult Intelligence Scale Revised (WAIS$\mathrm{R})$.

Visuospatial and visuoconstructive functions were assessed with the block design and picture completion subtests of the WAIS-R. The digit span and digit symbol subtests of the WAIS-R were used to assess working memory. Verbal learning and memory were assessed with the logical memory subtest of the Wechsler Memory ScaleRevised (WMS-R) and the word list subtest of the Wechsler Memory Scale-Third Edition (WMS-III). Visual memory was assessed with the visual reproduction subtest of the WMS-R. Verbal fluency was assessed with two tests; 
at first the subject was asked to list as many animals in a minute as he/she could and then words that begin with the letter $\mathrm{K}$.

Executive function was assessed with two traditional neuropsychological tests as well as computerized tasks. Of the traditional tests, Trail making and Rule shift cards tests from Behavioral Assessment of the Dysexecutive syndrome (BADS) were used. Computerized tasks included seven tasks from the Cognispeed (C) for Windows 1.0 software (Revonsuo and Portin 1995). Reaction times were measured with simple-, two-choice- and ten-choice-tasks. Subtraction-, statement verification- and Stroop-type tasks were used to assess controlled cognitive processing and attention. Stroop effect was measured using two separate colour-word naming tests. First the subjects were asked to read colour names written in concordant colour (e.g., blue written in blue) to measure facilitation and then in discordant colour (e.g., red written in blue) to measure interference. Vigilance task was used to measure sustaining attention. This is a monotonous task lasting 15 min during which letters appear on the screen. Among them are two target letters occurring at random in a relatively slow rate.

\section{Statistics}

The statistical analysis was carried out using IBM SPSS Statistics 20 software. Due to the small sample size and non-normal distribution of some of the data, only nonparametric tests were applied. Kruskal-Wallis Test for Several Independent samples was used to analyze overall variance in the neuropsychological performance. The N100 latency median, P200 latency median and N100 amplitude habituation median were used as a grouping variable in the respective analysis. Mann-Whitney test was used to compare the mean latencies and amplitudes of N100 and P200 potentials and Spearman rank to measure correlation between the neurophysiological and neuropsychological parameters.

\section{Results}

The PD-patient's and controls clinical and demographic characteristics as well as the latencies and amplitudes of N100 and P200 are described in Table 1. Three patients did not attend to the neuropsychological evaluation leaving 15 patients for the respective analysis. The patients and controls were age matched apart from one outlier in the patient group (a 43 year old woman). The statistical analysis was repeated after the exclusion of the outlier and the results did not change significantly.

The N100 latency was prolonged in the patients compared to the controls with borderline significance (Mann-
Whitney, $p=0.05)$. There were no other significant differences in the N100 and P200 latencies or amplitudes between the two groups. Figure 1 shows the ERP grand averages for the patients and controls. The habituation of the N100-amplitude was more pronounced in the controls compared to the patients, though this finding did not reach statistical significance.

In the Kruskal-Wallis test the performance in several neuropsychological tests varied according to N100 latency and amplitude habituation but there was no variance with respect to the P200 latency. The results of the KruskalWallis test are displayed in Table 2. The neuropsychological tests with statistically significant variance were chosen for further statistical analysis.

In the patient group, the N100 latency showed a significant negative correlation with the delayed visual reproduction of the WMS-R (Spearman rank $R=-0.62$, $p=0.010$ ) and a trend towards negative correlation with the immediate recall of the word list of the WMS-III (Spearman rank $R=-0.53, p=0.056$ ). Habituation of the N100-amplitude correlated with delayed visual reproduction (Spearman $\operatorname{rank} R=0.57, p=0.026$ ). The patients were divided into two groups according to the median of the delayed visual reproduction result. The patients with above median result had shorter N100 latencies and stronger habituation as shown in Table 3.

There was no correlation between the N100 latency or habituation and age, disease duration from the diagnosis, UPDRS-motor score and daily levo-dopa dose in the patients.

\section{Discussion}

In the present study the N100 latency was prolonged in PDpatients compared to healthy controls. This finding is in accordance with previous studies by Jiang et al. (2000) and Raudino et al. (1997). The latter also performed neuropsychological testing but did not find an association between cognition and the N100-potential. Interestingly, the N100 latency has been reported normal in a previous study concerning amnestic MCI and Alzheimer's disease (Lai et al. 2010) suggesting that prolonged latency of the N100 might aid in differentiating PD-related cognitive decline from these other common neurocognitive disorders.

The association of the N100 latency and amplitude habituation with a visual working memory task is interesting considering that problems in visuospatial abilities and working memory are common even in the early stages of PD (Aarsland et al. 2008; Kandiah et al. 2009; Muslimovic et al. 2005; Uc et al. 2005). Although at this stage the neuropathological changes of PD are confined to brain stem and basal ganglia (Braak et al. 2003), the ensuing 

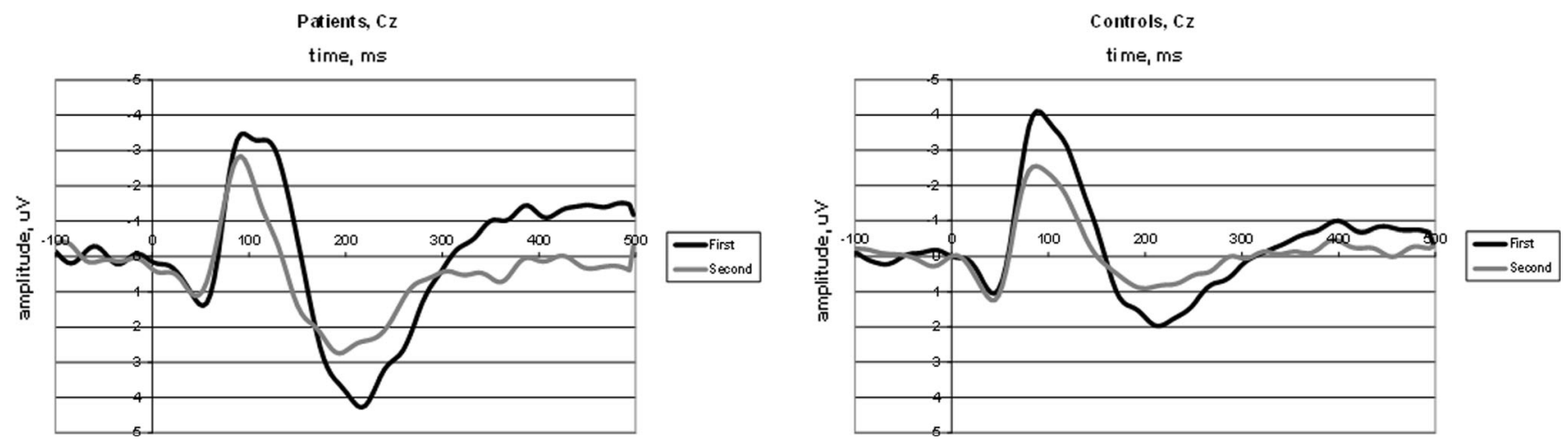

Fig. 1 Auditory event-related potentials in response to the first (black) and second (gray) tone of a pair of tones (ISI 0.5s) measured at the central (Cz) electrode location

Table 2 The results of the Kruskal-Wallis analysis of variance

\begin{tabular}{lll}
\hline Neuropsychological & Grouping & Grouping \\
test & variable & variable \\
& N100 & N100 amplitude \\
Latency & habituation \\
& median & median \\
\hline
\end{tabular}

Verbal fluency (animals)

Verbal fluency (letter K)

Rule shift cards

Word list A (immediate)

$$
\begin{array}{r}
p=0.03 \quad p=0.04 \\
p=0.03
\end{array}
$$

Word list $\mathrm{B}$

Word list A (delayed)

Logical story

Visual reproduction

(immediate)

Visual reproduction (delayed)

$p=0.003$

$p=0.02$

Digit span

Similarities

Picture completion

Block design

Trail making A

Trail making B

Simple reaction time

Two-choice reaction time

Ten-choice reaction time

Subtraction

Statement verification

Stroop

Stroop (interference)

Vigilance

dopaminergic defect disturbs connections between striatum and frontal cortex. This frontostriatal dysfunction leads to early cognitive alterations such as poor attention and diminished working memory capacity (Jokinen et al. 2013; Lewis et al. 2003). Attention and working memory capacity are closely interconnected as previous studies
Table 3 The difference between the N100 latency and amplitude habituation in the patient groups defined by the performance in the delayed visual reproduction test

\begin{tabular}{clll}
\hline & $\begin{array}{l}\text { Delayed visual } \\
\text { reproduction } \\
\text { above median } \\
(n=7)\end{array}$ & $\begin{array}{l}\text { Delayed visual } \\
\text { reproduction below } \\
\text { median }(n=8)\end{array}$ & $\begin{array}{l}\text { Mann- } \\
\text { Whitney }\end{array}$ \\
\hline $\begin{array}{c}\text { N100 Latency, } \\
\text { mean (SD) }\end{array}$ & $95.5(11.6)$ & $131.7(21.9)$ & $p=0.07$ \\
$\begin{array}{c}\text { N100 Amplitude } \\
\text { habituation, } \\
\text { mean (SD) }\end{array}$ & $-1.7(1.8)$ & $-3.4(1.6)$ & $p=0.04$ \\
\hline
\end{tabular}

indicate that working memory is under attentional control that is mediated by basal ganglia (Fielding et al. 2006; Lee et al. 2010; McNab and Klingberg 2008). The memory problems in PD may, therefore, partly be due to poor ability to filter out irrelevant information from taking space in easily overloading working memory. The N100 evoked response potential is considered a measure of focusing attention, demanding also suppression of irrelevant stimuli. The patients' difficulty in focusing attention would, therefore, explain the close connection of prolonged N100 latency and poor amplitude habituation with the visual working memory task. This hypothesis is in conjunction with previous work presented by Lijffijt et al. (2009), Brumback et al. (2004) and Soininen et al. (1995), who found N100 response to be associated with visual working memory and working memory span. The studied subjects were healthy volunteers from a community sample as there are no studies including PD-patients. These previous studies increase our knowledge of the N100 potential as a measure of attention and working memory although the number of subjects in the studies has been rather low. Also our results must be interpreted with caution considering the small sample size. Larger studies are needed to corroborate our findings and also to better control for possible confounding factors such as medication and mood. 
Why haven't the previous studies found consistently prolonged N100 latency or altered N100 habituation in PD? All previous studies, as well as ours, include only a small number of patients with a large spectrum of age, duration of disease and disease severity. The statistical power to detect subtle differences in these patient samples has been rather low. Also methodological differences in EEG-ERP recordings and signal averaging may explain the inconsistent findings.

The treatment of cognitive decline remains an enigma. There is some evidence that life style factors such as exercising and social activity, as well as optimal treatment of vascular risk factors may help to preserve cognition in neurodegenerative diseases such as PD (Ngandu et al. 2015). Exercise has also been found to cause augmentation of the N100 amplitude in healthy elderly adults (Chang et al. 2013) and our findings further supports regular exercise as a part of PD treatment regimen.

The obvious limitation of our study is the small sample size, with many PD-patients not participating because of the laborious protocol.

We conclude that prolonged N100 latency and poor amplitude habituation have interesting associations with visual working memory in PD. Ours study adds to knowledge of the mechanisms of working memory impairment in PD and corroborates previous findings that link attention and working memory capacity. As to date there is too little information to judge if a clinical application of ERP-measurement would be useful in the diagnosis of cognitive decline and dementia in PD.

Acknowledgements We thank Petra Keski-Säntti, MD, for her contribution in the gathering of the patient data.

\section{Compliance with ethical standards}

Conflict of interest We declare that we have no conflict of interest.

\section{References}

Aarsland D, Andersen K, Larsen JP, Lolk A, Kragh-Sorensen P (2003) Prevalence and characteristics of dementia in parkinson disease: An 8-year prospective study. Arch Neurol 60(3):387-392

Aarsland D, Bronnick K, Larsen JP, Tysnes OB, Alves G, For the Norwegian ParkWest Study Group (2008) Cognitive impairment in incident, untreated parkinson disease: the norwegian ParkWest study. Neurology. doi:10.1212/01.wnl.0000338632.00552. $\mathrm{cb}$

Annanmaki T, Pessala A, Hokkanen L, Murros K (2008) Uric acid associates with cognition in parkinson's disease. Parkinsonism Relat Disord 14(7):576-578. doi:10.1016/j.parkreldis.2007.11.001

Bennys K, Rondouin G, Benattar E, Gabelle A, Touchon J (2011) Can event-related potential predict the progression of mild cognitive impairment? J Clin Neurophysiol 28(6):625-632. doi:10.1097/ WNP.0b013e31823cc2d3
Braak H, Del Tredici K, Rub U, de Vos RA, Jansen Steur EN, Braak E (2003) Staging of brain pathology related to sporadic parkinson's disease. Neurobiol Aging 24(2):197-211

Brumback CR, Low KA, Gratton G, Fabiani M (2004) Sensory ERPs predict differences in working memory span and fluid intelligence. NeuroReport 15(2):373-376

Chang YK, Huang CJ, Chen KF, Hung TM (2013) Physical activity and working memory in healthy older adults: an ERP study. Psychophysiology 50(11):1174-1182

Chen KJ, Lin RT, Liu CK, Tai CT, Lai CL (2006) Relationship between event-related potentials and frontal-subcortical dysfunction in parkinson's disease. Parkinsonism Relat Disord 12(7):453-458

Ebmeier KP, Potter DD, Cochrane RH, Crawford JR, Stewart L, Calder SA, Salzen EA (1992) Event related potentials, reaction time, and cognitive performance in idiopathic Parkinson's disease. Biol Psychol 33(1):73-89

Emre M, Aarsland D, Brown R, Burn DJ, Duyckaerts C, Mizuno Y, Dubois B (2007) Clinical diagnostic criteria for dementia associated with parkinson's disease. Mov Disord 22(12):1689-1707. doi:10.1002/mds.21507 (quiz 1837)

Fielding J, Georgiou-Karistianis N, White O (2006) The role of the basal ganglia in the control of automatic visuospatial attention. J Int Neuropsychol Soc 12(5):657-667. doi:10.1017/ S1355617706060784

Goodin DS, Aminoff MJ (1987) Electrophysiological differences between demented and nondemented patients with parkinson's disease. Ann Neurol 21(1):90-94. doi:10.1002/ana.410210116

Green J, Woodard JL, Sirockman BE, Zakers GO, Maier CL, Green RC, Watts RL (1996) Event-related potential P3 change in mild parkinson's disease. Mov Disord 11(1):32-42. doi:10.1002/mds. 870110108

Hansch EC, Syndulko K, Cohen SN, Goldberg ZI, Potvin AR, Tourtellotte WW (1982) Cognition in parkinson disease: an event-related potential perspective. Ann Neurol 11(6):599-607. doi:10.1002/ana.410110608

Hasey GM, Kiang M (2013) A review of recent literature employing electroencephalographic techniques to study the pathophysiology, phenomenology, and treatment response of schizophrenia. Curr Psychiatry Rep. doi:10.1007/s11920-013-0388-x

Hayashi R, Hanyu N, Kurashima T, Tokutake T, Yanagisawa N (1996) Relationship between cognitive impairments, eventrelated potentials, and motor disability scores in patients with parkinson's disease: 2-year follow-up study. J Neurol Sci 141(1-2):45-48

Hozumi A, Hirata K, Tanaka H, Yamazaki K (2000) Perseveration for novel stimuli in parkinson's disease: an evaluation based on event-related potentials topography. Mov Disord 15(5):835-842

Hughes AJ, Daniel SE, Kilford L, Lees AJ (1992) Accuracy of clinical diagnosis of idiopathic parkinson's disease: a clinicopathological study of 100 cases. J Neurol Neurosurg Psychiatry 55(3):181-184

Ille N, Berg P, Scherg M (2002) Artifact correction of the ongoing EEG using spatial filters based on artifact and brain signal topographies. J Clin Neurophysiol 19(2):113-124

Jiang C, Kaseda Y, Kumagai R, Nakano Y, Nakamura S (2000) Habituation of event-related potentials in patients with parkinson's disease. Physiol Behav 68(5):741-747

Jokinen P, Karrasch M, Bruck A, Johansson J, Bergman J, Rinne JO (2013) Cognitive slowing in parkinson's disease is related to frontostriatal dopaminergic dysfunction. $\mathrm{J}$ Neurol Sci 329(1-2):23-28. doi:10.1016/j.jns.2013.03.006

Kandiah N, Narasimhalu K, Lau PN, Seah SH, Au WL, Tan LC (2009) Cognitive decline in early parkinson's disease. Mov Disord 24(4):605-608. doi:10.1002/mds.22384

Katsarou Z, Bostantjopoulou S, Kimiskidis V, Rossopoulos E, Kazis A (2004) Auditory event-related potentials in parkinson's 
disease in relation to cognitive ability. Percept Mot Skills 98(3 Pt 2):1441-1448

Lai CL, Lin RT, Liou LM, Liu CK (2010) The role of event-related potentials in cognitive decline in alzheimer's disease. Clin Neurophysiol 121(2):194-199. doi:10.1016/j.clinph.2009.11.001

Lee EY, Cowan N, Vogel EK, Rolan T, Valle-Inclan F, Hackley SA (2010) Visual working memory deficits in patients with parkinson's disease are due to both reduced storage capacity and impaired ability to filter out irrelevant information. Brain $\mathbf{J}$ Neurol 133(9):2677-2689. doi:10.1093/brain/awq197

Lewis SJ, Dove A, Robbins TW, Barker RA, Owen AM (2003) Cognitive impairments in early parkinson's disease are accompanied by reductions in activity in frontostriatal neural circuitry. J Neurosci 23(15):6351-6356

Lijffijt M, Lane SD, Meier SL, Boutros NN, Burroughs S, Steinberg JL, Swann AC (2009) P50, N100, and P200 sensory gating: relationships with behavioral inhibition, attention, and working memory. Psychophysiology 46(5):1059-1068. doi:10.1111/j. 1469-8986.2009.00845

Litvan I, Goldman JG, Troster AI, Schmand BA, Weintraub D, Petersen RC, Emre M (2012) Diagnostic criteria for mild cognitive impairment in parkinson's disease: movement disorder society task force guidelines. Mov Disord 27(3):349-356. doi: $10.1002 / \mathrm{mds} .24893$

McNab F, Klingberg T (2008) Prefrontal cortex and basal ganglia control access to working memory. Nat Neurosci 11(1):103-107

Muslimovic D, Post B, Speelman JD, Schmand B (2005) Cognitive profile of patients with newly diagnosed parkinson disease. Neurology 65(8):1239-1245

Ngandu T, Lehtisalo J, Solomon A, Levalahti E, Ahtiluoto S, Antikainen R, Kivipelto M (2015) A 2 year multidomain intervention of diet, exercise, cognitive training, and vascular risk monitoring versus control to prevent cognitive decline in atrisk elderly people (FINGER): a randomised controlled trial. Lancet (Lond, Engl), 385(9984), 2255-2263. doi:10.1016/ S0140-6736(15)60461-5

Pekkonen E, Jousmaki V, Reinikainen K, Partanen J (1995) Automatic auditory discrimination is impaired in parkinson's disease. Electroencephalogr Clin Neurophysiol 95(1):47-52
Pfeiffer HC, Lokkegaard A, Zoetmulder M, Friberg L, Werdelin L (2014) Cognitive impairment in early-stage non-demented parkinson's disease patients. Acta Neurol Scand 129(5):307-318. doi:10.1111/ ane.12189

Pigott K, Rick J, Xie SX, Hurtig H, Chen-Plotkin A, Duda JE, Weintraub D (2015) Longitudinal study of normal cognition in parkinson disease. Neurology. doi:10.1212/WNL.0000000000002001

Raudino F, Garavaglia P, Beretta S, Pellegrini G (1997) Auditory event-related potentials in parkinson's disease. Electromyogr Clin Neurophysiol 37(7):409-413

Revonsuo A, Portin R (1995) CogniSpeed the computer based measurement of cognitive processing. University of Turku, Aboa Tech Ltd, Turku

Riedel O, Klotsche J, Spottke A, Deuschl G, Forstl H, Henn F, Wittchen HU (2008) Cognitive impairment in 873 patients with idiopathic parkinson's disease. Results from the german study on epidemiology of Parkinson's disease with dementia (GEPAD). J Neurol 255(2):255-264. doi:10.1007/s00415-008-0720-2

Soininen HS, Karhu J, Partanen J, Paakkonen A, Jousmaki V, Hanninen T, Koivisto K (1995) Habituation of auditory N100 correlates with amygdaloid volumes and frontal functions in ageassociated memory impairment. Physiol Behav 57(5):927-935

Tsuchiya H, Yamaguchi S, Kobayashi S (2000) Impaired novelty detection and frontal lobe dysfunction in parkinson's disease. Neuropsychologia 38(5):645-654 ([pii]: S0028-3932(99)001086)

Uc EY, Rizzo M, Anderson SW, Qian S, Rodnitzky RL, Dawson JD (2005) Visual dysfunction in parkinson disease without dementia. Neurology 65(12):1907-1913. doi:10.1212/01.wnl. 0000191565.11065 .11

Vieregge P, Verleger R, Wascher E, Stuven F, Kompf D (1994) Auditory selective attention is impaired in parkinson's diseaseevent-related evidence from EEG potentials. Brain Res Cogn Brain Res 2(2):117-129. doi:10.1016/0926-6410(94)90008-6 